\title{
Design-based research as an informal learning model for choral conductors
}

\author{
Naomi Cooper* \\ Western Sydney University
}

\begin{abstract}
The number of community choirs continues to grow, and literature endorsing the benefits of choral singing for physical, mental and emotional health and well-being is rapidly expanding, meaning that the professional development of community choral conductors is in the public interest. However, research on choral conductor education remains limited. Theoretical perspectives on choral conductor training presented by Varvarigou and Durrant (20I I) have provided a useful framework for conceptualizing a formal training model. As opportunities to study using such a model are not widely available in Australia and other locations, it is pertinent to consider alternative methods for community choral conductors to learn the craft and develop their skills. A design-based research model has been proposed as a possible format for learning choral conducting and the case study of the author's own practice reported here reveals its effectiveness. The design-based research structure, incorporating observation and interview with ten professional choral conductors, as well as cycles of design, intervention and evaluation is proposed as a possible informal learning approach for other choral conductors.
\end{abstract}

Keywords: choral conducting; community choir; design-based research

\section{Introduction}

There are many community choirs across Australia and as the number of choirs grows, so too does the wealth of literature endorsing the benefits of choral singing for physical, mental and emotional health and well-being (Bailey and Davidson, 2005; Beck et al., 2000; Bungay et al., 20 I0; Clift and Hancox, 2010; Gridley, 2010; Kreutz et al., 2004; Unwin et al., 2002). The professional development of community choral conductors is therefore in the public interest. However, few formal training opportunities exist for these conductors and research on choral conductor education remains limited. Consequently, a doctoral research study explored the viability of an informal learning approach for choral conducting. A design-based research methodology combined input from experienced choral conductors (through observation and professional conversations) with a cyclical process of trialling interventions in my own practice in order to develop skills in choral conducting.

\section{The community choir context in Australia}

In Australia, community choirs have continued to evolve, and recent decades have seen a rejuvenation of the community choir scene, where a philosophy of democratization and

\footnotetext{
* Email: naomi@naomicooper.com.au

(C) Copyright 2017 Cooper. This is an Open Access article distributed under the terms of the Creative Commons Attribution Licence, which permits unrestricted use, distribution and reproduction in any medium, provided the original author and source are credited.
} 
secularization has led to greater participation in choral singing (Rickwood, 2010). Church choirs and traditional choral societies performing classical choral repertoire dominated the landscape for some time. While these groups still exist, community choirs have diversified and there are now many choirs performing multicultural, folk/traditional, pop/contemporary, barbershop, African-American gospel, musical theatre or a combination of repertoire, to the point that classical choirs constitute only 20 per cent of Australian choirs (Masso, 20I3). If professional choirs are defined to be choirs where choristers are remunerated financially for their work, there are very few professional choirs in Australia (Cantillation and The Song Company are two such groups). There are a small number of semi-professional groups, but the majority are amateur groups, usually referred to as community choirs. Entry requirements are also indicative of the nature of choirs across Australia. According to a 2013 survey, 'about one in five choirs audition their members, which means the vast majority have an "open door" policy' (Masso, 2013: 8). Only 8 per cent of choirs require singers to be able to read music, and for nonauditioned choirs it is only I per cent. Members of community choirs in Australia have larger proportions of older members: 'almost two thirds of choir members are over 45' years of age, and the 'highest proportion of participants are in the 55-64 age category' (Masso, 2013: $5)$. Women are also much more strongly represented than men, with an estimated 70 per cent of choir members being female (Masso, 20I3: 6). Choral conductors (often referred to as choir directors or choir leaders) work in both voluntary (4I per cent) and paid (59 per cent) capacities and most (95 per cent) have had musical training, with 69 per cent having completed a degree related to music and 58 per cent of those having a degree in education (Masso, 2013: 7). While it is difficult to determine the number of community choirs in Australia, 'it seems likely that there are well over 1000 choirs, [and] there may in fact be several thousand' (Masso, 20 I3: 12). The large number of community choirs around Australia (and internationally) requires a workforce of choral conductors that are appropriately equipped for the role.

\section{Literature: Choral conducting education}

This demand for choral conductors means that choral conductor education is important. In Australia, there are limited options for community choral conductor training. There are many textbooks on choral conducting, and these provide a rich source of information for learning and practising choral conductors. They provide detailed examination of many facets of choral conducting, such as conducting technique (beat patterns, gesture and body language), the multiple roles of the choral conductor (conductor, educator and administrator), rehearsal technique, vocal pedagogy (vocal health, warm-ups, posture, breathing, voice change, intonation, blend, balance, tone and diction), repertoire selection and score analysis (Backhouse, 1995; Backhouse, 2010; Brewer, 2004; Brinson, 1996; Busch, 1984; Collins, 1993; DiFrances, 2006; Durrant, 2003; Fredrickson, 2004; Garretson, 1998; Gorelick, 200I; Gumm, 2010; Holst, 1973; Hylton, 1995; Jordan and Mehaffey, 200I; Kemp, 2009; McGill and Volk, 2007; McRae, 199I; Neuen and Bonamico, 2002; Roe, 1994).

While books of this kind are valuable resources, the skills of choral conducting require practical experience. Specialized degree programmes are not available in Australia and only a few degree programmes offer units of study on choral conducting. Those units tend to focus on technical musical skills rather than on the philosophical, pedagogical, leadership and interpersonal skills that are also essential to the role (Durrant, 2003). Workshops and masterclasses are the main source of professional development for choral conductors and they are spread across a country spanning huge distances. 
The nature of training for choral conductors in Australia has many parallels with the UK, which Durrant suggests 'could be perceived as unsystematic and unstructured' compared to the USA, "where a large number of systematic and structured programmes throughout the country allow students to "major" in the area of choral conducting' (1994: 74). Across the United States, students can study choral conducting at bachelor, master and doctoral levels at many different universities (Hensley, 2004; White, 1982). In addition to the lack of training in the UK, Varvarigou and Durrant (20I I) identified a paucity of research on the training of choral conductors, particularly outside of the USA. They explored theoretical perspectives on choral conductor education and proposed a possible training framework.

The framework outlined three theoretical perspectives on the training of choral conductors: effective teaching and learning environments, cognitive apprenticeship contexts and theories of expertise. Teaching and learning environments in higher education and the workplace were described as an 'interactive system' between the learner, the subject matter and the environment (Varvarigou and Durrant, 20II: 328). The cognitive apprenticeship 'enquires into teaching the processes that experts use to handle complex tasks and on learning through guided experience on cognitive (subject knowledge) and metacognitive (self-correction, selfmonitoring) levels, rather than physical skills and processes' (Varvarigou and Durrant, 20II: 328). This involves on-the-job learning where 'the apprentice observes the master modelling the target process. The apprentice then attempts to execute the process with coaching from the master ... As the learner develops increasing skill, the master provides less help, eventually fading away completely' (Anderman and Anderman, 2009: 177). Theories of expertise indicate that expertise in choral conducting develops 'thorough deliberate practise', not charisma as is sometimes suggested (Varvarigou and Durrant, 20I I: 329). However, it is identified that 'the issue regarding choral conductors and practising is that they can only effectively practise in front of a choir' (Varvarigou and Durrant, 20I I: 330).

\section{Learning to conduct community choirs through informal learning}

The impetus for this study was the researcher's own desire to learn to conduct community choirs in spite of a lack of formal training avenues. If there is not a course available, as is the case in Australia, how else might a choral conductor facilitate her own learning? I decided to use an informal learning structure to develop my skill set as a choral conductor. Informal learning is defined to be 'predominantly experiential and non-institutional' and is characterized by 'situations outside the classroom that are not designed in any detail, but that are planned' (Marsick and Watkins, 2015: 7). Two research questions were developed in planning the informal learning process:

(I) What approaches and strategies do community choral conductors employ?

(2) How can a novice choral conductor put these approaches and strategies into practice with community choirs?

\section{Methodology: Design-based research applied to the learning choral conductor}

In order to address the two research questions together, I sought a research design that would investigate the practice of experienced choral conductors, incorporate knowledge from the conductors into my own choral conducting and could then lead to the development of a possible model for choral conductors' learning. Design-based research is a cyclical methodology 
where each iteration of the cycle is informed by previous iterations, so that it 'advances design, research and practice concurrently' (Wang and Hannafin, 2005: 5). This methodology acted as a wide umbrella to encapsulate a range of methods and successfully addressed both research questions by yoking them together through the design-based research methodology. The design involved observation of, and professional conversations with, experienced community choral conductors, which addressed the first research question, 'What approaches and strategies do community choral conductors employ?' It also included my own reflective practice and reflexivity, which were evaluated through the data analysis process, and the results fed back into the next cycle, eventually leading to new theoretical and practical understandings. These cycles formed the response to the second research question, 'How can a novice choral conductor put these approaches and strategies into practice with community choirs?' Figure I depicts how the design-based research process was applied to my choral conducting practice.

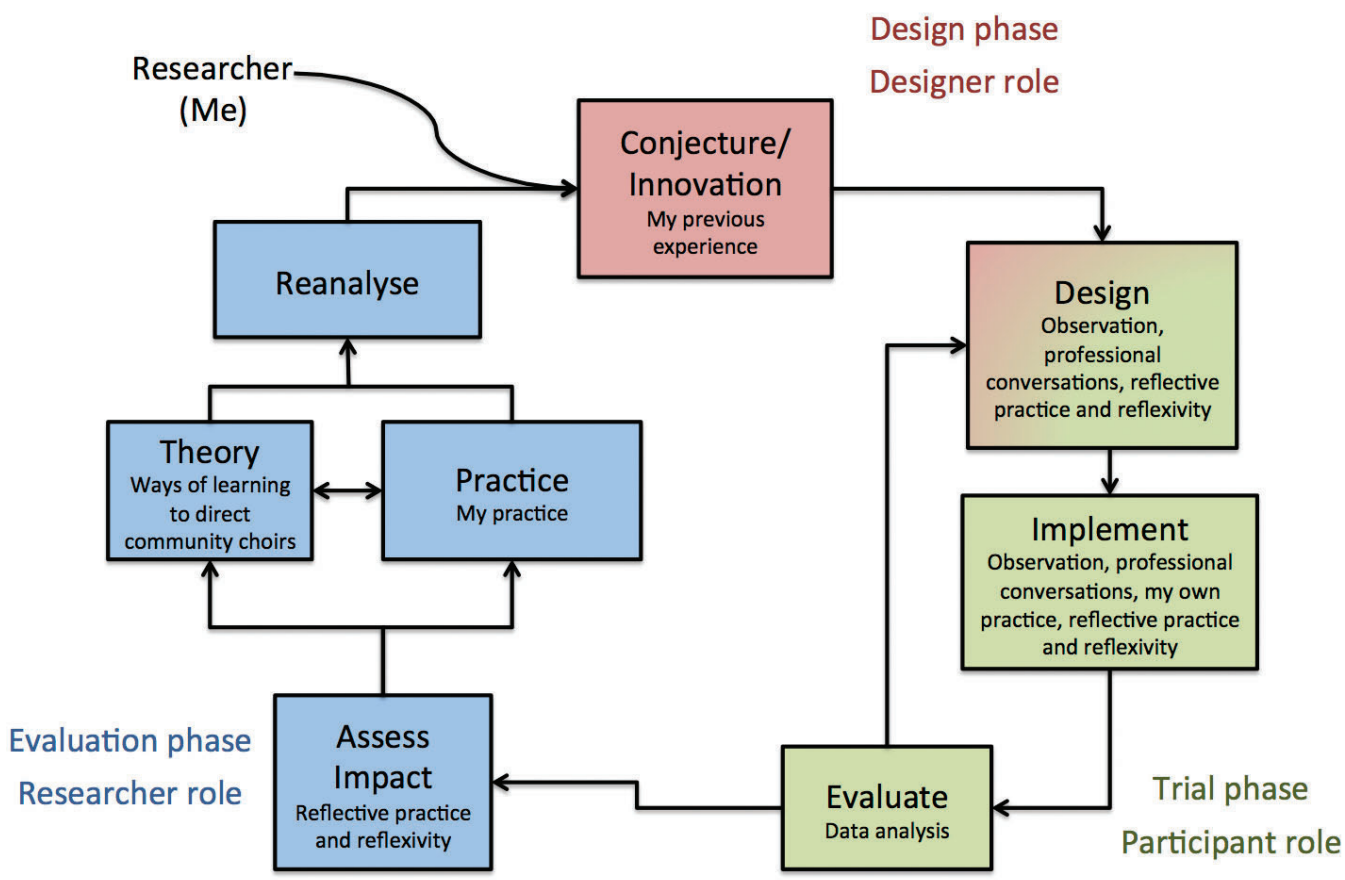

Figure I: Design-based research model for the learning choir conductor (based on Wang and Hannafin, 2005)

Design-based research is defined as a 'systematic but flexible methodology aimed to improve educational practices through iterative analysis, design, development, and implementation, based on collaboration among researchers and practitioners in real-world settings, and leading to contextually-sensitive design principles and theories' (Wang and Hannafin, 2005: 6-7). It is described as pragmatic, grounded, interactive, iterative and flexible, integrative, and contextual (Wang and Hannafin, 2005: 6-7).

The project embraced pragmatism because I, as both researcher and practitioner, designed interventions within my own practice derived from observation and interview of professional choral conductors. This directly impacted on my practice, and has therefore contributed to solving the real-world problems I have experienced within my practice. This has the potential to enhance the practice of other choral conductors through the model presented here. 
This research was grounded in the real-world context of the choral rehearsal as well as in the existing literature on choral conducting. The written output of the work is contributing to both choral and educational discourses (Cooper, 20I3a; Cooper, 20I3b; Cooper, 20I4; Cooper, in press; Hughes et al., 2014).

The concept of interaction arose between me and the professional choral conductors I observed and interviewed, between me and the choirs I conduct, and between me and my own choral conducting. I needed to successfully negotiate these differing roles through iterative processes, that is, cycles of observations, trials and evaluations of each rehearsal. The methodology gave flexibility to the research project design, which allowed me to react to experiences within my practice. The research used a variety of research methods, including observation, professional conversation, reflective practice (Schön, 1983; Schön, 1987) and reflexivity (aspects of autoethnography - me in the conducting environment, keeping a journal and video analysis), in order to document the practice from a range of perspectives. As there was no external researcher (I was deeply involved in the practice, not an objective outsider), documentation of the design process needed to be very rigorous.

The research was contextual because I documented the application of the design-based research process to the choral environment. In this case, I was the 'designed artefact' (Joseph, 2004), that is, I designed interventions within my own choral conducting practice to facilitate more effective learning of the practice. These designed interventions stemmed from the first part of my research (observation of, and professional conversations with, experienced choral conductors). They also stemmed from previous iterations of the design-based research cycles as described by Joseph: 'as theory and findings emerge from the research, they can shape not only the evolving design, but also the evolving research apparatus' (Joseph, 2004: 236). As a result, I have generated theory from this research pertaining to informal learning processes in the context of choral conducting.

\section{Design, trial and evaluation}

As can be seen in Figure I, the design-based research methodology facilitated ongoing cycles of design, trial and evaluation. Over the course of the three years of the research, observation of nine experienced choral conductors and professional conversations with ten experienced choral conductors were undertaken. I was concurrently conducting weekly rehearsals with my own choirs and writing reflective journal entries after each one. These included a combination of children's choirs, high-school choirs and adult community choirs, as well as university choir workshops. The skill levels of each of these groups varied; however, in all of the choirs I was conducting, there was a proportion of the group with little singing, choral and/or score-reading experience. The repertoire consisted of a cappella and accompanied pieces in diverse genres, including classical, popular, African-American gospel and traditional songs from many cultures around the world.

\section{Design}

The design phase consisted of ethnography-informed observation and professional conversations with experienced choral conductors. An ethnographic approach to observation was chosen for this project because it offered an 'insider's perspective' (Fetterman, 1989: 12) on the practice of professional choral conductors by providing 'rich, descriptive data about the contexts, activities, and beliefs of participants' (LeCompte and Preissle, 1993: 8). A sample of professional choral conductors were interviewed about their musical background, training, experience and 
practice of conducting community choirs. Owing to the nature of the relationship between the researcher and choral conductor - interviews consisting of an experienced choral conductor speaking with a novice choral conductor - these interviews took on many of the qualities of 'professional conversations' that are described in educational discourses. The Australian Institute for Teaching and School Leadership defines professional conversations as 'the formal and informal dialogue that occurs between education professionals including teachers, mentors, coaches and school leaders, which is focused on educational matters' (Timperley, 20I5: 6). Stemming from the view of 'knowledge as constructed in social acts and as situated and enacted in social communities of practice' (Orland-Barak, 2006: 15), professional conversations have been identified as having the potential for 'articulating, analysing and framing dilemmas and for solving pedagogical problems' (Orland-Barak, 2006: 16). The concept of the professional conversation therefore informed the nature and structure of the interviews. The interviews were conducted in a semi-structured way, so that the conversation could follow topics brought up by the participants. This semi-structured approach allowed the interview to feel more like a dialogue between two professionals, rather than a researcher asking questions of a participant. This was important because the professional choral conductors were more likely to have a sense of what was relevant to the practice than the novice choral conductor. This also allowed me, the novice choral conductor, to ask questions pertinent to my practice at that particular time, rather than adhering to a set of questions prepared at the outset of the project. In a way, these exchanges operated as a cognitive apprenticeship, enabling me to understand the conductors' thinking processes.

\section{Trial}

The trial phase applied interventions from themes that emerged through coding the observation and interview data. Observation notes, interview transcripts and my reflective journal were analysed through the coding of text data. This analysis adopted Glaser's (1965) constant comparative method, whereby codings are compared 'over and over again with codings and classifications that have already been made' (Flick, 2002: 23I). Initial coding sought to classify the data in terms of three key approaches established through the literature review: aural, visual and physical transmission (Cooper, in press). Data were also analysed based on the stages of introducing, rehearsing and performing a piece. Other themes emerged from the data set, and these impacted on subsequent observation and interview sessions. It became clear that initial codings were based on my own perspective as a choral conductor, examining what it was that a conductor was doing: whether they were saying something, using their body to show something, asking the singers to reflect something in their own bodies or something else. This was the result of my reflective practice and always asking myself, 'what is this conductor doing and how can I apply it to my own practice?' Following the data collection process, it became apparent that it was perhaps also useful to analyse the data in terms of the purpose of the conductor's action, that is, whether it was to address pitch, rhythm, blend or something else. Several subnodes appeared relevant; for example, under the node of 'pitch' it seemed that semitones were an important subcategory based on the frequency with which issues relating to semitones arose in the data. Other issues arose during the analysis, which resulted in new nodes being created to facilitate information that was not anticipated ahead of time.

Reflective practice and reflexivity formed the feedback process and were used to address the second research question: 'How can a novice choral conductor put these approaches and strategies into practice with community choirs?' Practitioners wishing to improve their practice across a range of professions use reflective practice. This has included medical, nursing, social 
work, counselling and education professions (Johns, 2009). It is especially useful for novices learning a practice, and choral conducting is no different. Bolton defined reflective practice as 'a process of learning and developing through examining our own practice, opening our practice to scrutiny by others, and studying texts from the wider sphere' (200I: 4). Reflective practice often involves writing about one's practice. While Bolton endorsed creative writing, many practitioners choose to keep a reflective journal. The learning possibilities of the reflective journal lie in the way that writing 'taps the unconscious; it can make the implicit explicit, and therefore, open to analysis' (Holly, 1989: 7I), and how 'keeping a personal, professional journal enables the author to develop an educational archive which serves as an evolving database for gaining understanding and insights which inform and enrich professional judgement' (Holly, 1989: 7I). In addition, 'writing about experience enables the author to view his/her experiences within broader contexts: social, political, economic and educational' (Holly, 1989: 75).

This ability to reveal tacit knowledge is of particular use to novices in developing their practice. While experts have a wealth of tacit knowledge from prior experience that they can draw on intuitively (rather than consciously), novices have not yet acquired this tacit knowledge. Schön's (1983; 1987) concepts of 'reflection-on-action' (reflecting after the event) and 'reflection-inaction' (pausing within one's practice to reconsider the situation and hopefully proceed towards the desired outcome) have had a significant impact on the processes of reflective practice. Creative practitioners have also found reflective practice and the reflective journal to be useful tools in shedding light on creative processes and how this can reveal an 'insider's perspective' (McIntyre, 2006: 4). Mclntyre argues that:
it is in revealing the understandings that lie behind a practitioner's 'feel' for their work that the possibility of practitioner-based research enquiry becomes a useful source of 'truth' about the creative process, especially if that process is theorised as being systemic by using the practitioner as an 'agent-experient'.

(Mclntyre, 2006: 6)

Reflective practice has been used by musicians, including both experienced and emerging wind conductors (Bartleet and Hultgren, 2008), and it has been applied in education contexts for some time (Barry, 1996; Roffey-Barentsen and Malthouse, 2013).

A reflective journal was used as the vehicle through which I explored my own choral conducting practice. Journal entries were recorded after each rehearsal to document and reflect upon my practice. While initial entries recounted what had happened in my rehearsals, before long I was able to reflect on strategies I had tried in rehearsal and how effective they had been, as well as beginning to analyse elements of my own practice.

In addition to reflective practice, reflexivity was another process used in analysis of my own practice throughout the research. Bolton states, 'reflexivity is making aspects of the self strange: focusing close attention upon one's own actions, thoughts, feelings, values, identity and their effect upon others, situations, and professional social structures' (200I: I0). Aspects of reflexivity were included in my journal as I considered my practice from different perspectives. This reflexivity was at times informed by scholarly literature and at other times by considering alternative perspectives proposed by my PhD supervisors at meetings. Thinking critically and reflexively about the effect of my own actions upon my choristers and the outcomes of my choral conducting practice became an integral part of the research. 


\section{Evaluation}

The evaluation phase consisted of data analysis of my reflective journal using the same constant comparative coding method as was used for the observation and interview transcripts. This evaluation fed into the design phase of the subsequent iteration of the cycle.

\section{Case study of the learning choral conductor}

I designed interventions in my own practice that were derived from the data analysis, which was ongoing throughout the process. Each rehearsal involved an iteration of the design, implementation and evaluation cycle depicted in Figure I. The cyclical design-based research approach enabled me to examine specific elements of the choral conducting practice in great detail and small changes sometimes had a significant impact on the effectiveness of strategies I used. Three examples of interventions in my own practice were procedures for giving starting pitches, use of verbal visual imagery and chorister use of visual reference, and these will be discussed below.

\section{Starting pitches}

The way in which I gave starting notes to a choir, particularly when working a cappella evolved following cycles of design-based research. At the start of the project, I would sing the notes in order from highest to lowest or lowest to highest, but as I observed other conductors, I realized that conductors would not always give starting notes in pitch order. This made me wonder about the reason for that and the justification for the order that conductors selected. I began experimenting with the sequence of the starting notes and realized that different voice parts had differing levels of confidence in remembering their starting pitch, and that this often also depended on the song. I trialled different options, such as singing the tonic first or last. When discussing the order in which she taught parts, one conductor said she would often teach the bass part first as they were most likely to get confused if they heard other parts before their own. She then taught the other parts, but would come back and briefly revise the bass part because they would sometimes forget their part after having heard all the other parts. I decided to apply the same principle to giving starting pitches by making sure I sang the note of the least confident vocal part last (or both first and last). This would vary depending on the choir I was working with and the song we were rehearsing. It was often one of the harmony parts, but in some cases those singing the melody had been placed on the melody line because they were not confident holding a part, so their note would be the final one to be sounded. Through this process my understanding evolved from thinking that the most effective order would be determined by the harmony of the song to determining that the skills of individual choristers and the confidence of each voice part shaped these decisions more strongly. Many cycles of design, intervention and evaluation led to the development of this strategy, which originated in observation, was informed by interview and was developed within my own practice.

\section{Verbal visual imagery}

The choral conductors in the study used several types of imagery in their practice. Visual imagery was used both physically (through gesture) and verbally. My use of speech in rehearsal has developed through the design-based research process. Having read about the merits of limiting the use of speaking in rehearsal (Gumm, 20I0), I have worked hard to ensure I speak only when 
absolutely necessary. I found through video analysis that verbal direction is my default strategy in rehearsals, particularly when my use of gesture is not achieving the desired outcome. While confident speaking in front of a group, I sometimes find it challenging to be direct and articulate when I am reacting 'on the fly' to the choir. I am capable of being much more articulate when I have had time to think about what I want to say. I knew this to be the case, but watching videos of myself speaking in rehearsals and workshops highlighted this for me.

Observing expert community choral conductors revealed the effectiveness of verbal visual imagery. I have struggled with this as a strategy because my own tendency is to use technical language (musical terminology and vocal physiology) rather than imagery (using visual images to evoke a vocal outcome). Realizing the strength of being able to use imagery as well as direct instructions, I sought to improve in this area. I designed interventions in my practice where I would use other conductors' images in my own rehearsals and had some success. One example of when I used another conductor's imagery was asking singers to 'imagine that you are about I5 kilo bigger than you actually are'. The sopranos were singing with a light and airy tone, when I needed the melody line to be strong and punchy. While this imagery helped a little, it was not a complete solution to the problem. I also tried using imagery suggested by choral conductors in books, such as Nancy Telfer's image of a spinning orange for improving tone quality. She suggested singers 'think of the sound as an orange spinning at forehead level' and 'spin the sound directly to the conductor' (1995: 36), which worked effectively for me and my singers. Other interventions included preparing verbal visual imagery of my own for a particular outcome in advance of the rehearsal.

After structuring my use of verbal visual imagery in this way, in one rehearsal I needed the choir I was conducting to sing much more legato (smoothly). I said, 'imagine you're moving through water' and encouraged the singers to 'hold on to the note as long as you possibly can before moving on to the next note'. To my delight, the combination of these images, along with smooth, flowing gestures that reflected this, greatly improved the choir's use of legato. I was struck by the fact that I had managed to use impromptu imagery. These were images I had heard other conductors use before, but I had not made plans in advance to use them. With continued practice I hope to be able to use spontaneous imagery more consistently and effectively.

\section{Chorister visual reference}

Choristers were observed using a range of visual references to assist their learning, including musical scores and lyric sheets, while other groups did not use either of these. My use of visual references for choristers has developed through iterations of the design-based research process. Having read about the benefits of aural transmission in the literature (Backhouse, 2010; Chadwick, 20II; Kennedy, 2009; Townsend, 1996), I was eager to use the approach with my choirs and to develop my own skills in teaching aurally. With my first community choir, I resisted providing a score for the singers because I wanted them to listen to me and to each other more than I wanted them to read notes from a score. I had also observed other conductors teaching songs in four-part harmony without giving choristers scores and I could not see why it would not work for me. Before I conducted them, the choir had always used scores, and the poor blend and intonation indicated to me that they needed to learn to listen more, instead of concentrating on their scores. I taught the South African song 'Somagwaza' without distributing scores. The song has three parts, and each part is only three bars in length, so I thought this would be relatively straightforward and a good choice for a song to learn aurally. What I had underestimated, however, was the extent to which the singers would feel insecure without a score or lyric sheet. They were so unsettled by a different approach compared to 
what they were used to, and worried that they would not be able to remember the words or music, that they did not listen well at all, which defeated the purpose completely. After realizing that the score made the singers much more comfortable, I provided them with copies. That experience caused me to reflect on my use of scores, and how I could best use both approaches in tandem. In my subsequent observations, I noticed that the majority of choral conductor participants provided scores to choristers most of the time, even when the teaching was done aurally. This gave singers the option to use the score or not as they wished, and the conductor taught parts aurally regardless. I spent many design-based research cycles experimenting with different combinations of using or not using scores and how to introduce them. There are now times when I prefer singers to learn part of a song before I give them a score, for a variety of reasons: reading a foreign language from a page can be more difficult than hearing the sounds first (because of singers' unfamiliarity with the language in spoken and/or written form); some rhythms, particularly syncopated ones, need to be felt rather than read to be the most effective (owing to singers' unfamiliarity with rhythm notation); singers learn differently when learning by ear compared to learning from a score (because they use their ears, rather than their eyes); and timbre (which may not be notated) can be more important than pitch and rhythm for some pieces. If I have a score available and the singers request it, it is now provided by the end of the first session because managing the anxiety of singers usually outweighs my preferred teaching process. Now I will usually tell them that I will give them a score, just not yet, and sometimes give them a reason for this. At other times, however, I do not give a reason because I do not want them to overthink my strategy.

While these three examples provide a snapshot of a few of the ways in which the designbased research methodology successfully improved a novice choral conductor's practice, how can the effectiveness of the model be evaluated? As this was a case study of one learning choral conductor, it is difficult to draw comparisons. However, it can be noted that at the commencement of the research project, I had limited skills and experience as a community choral conductor. Over the course of the study, as my skills developed, I was hired to conduct an assortment of choirs, including adult community choirs, school choirs, youth choirs and children's choirs, as well as to teach a university choir module. By the completion of the project, I was working full-time as a freelance choral conductor. I had also developed a significant support network of experienced choral conductors.

\section{Conclusion}

Theoretical perspectives on choral conductor training presented by Varvarigou and Durrant (20II) have provided a useful framework for conceptualizing a formal training model. As opportunities to study using such a model are not widely available in Australia and other locations, it is pertinent to consider alternative methods for community choral conductors to learn the craft and develop their skills. A design-based research model successfully addressed two research questions that structured a choral conductor's informal learning. The first question, 'What approaches and strategies do community choral conductors employ?' was answered through observation and professional conversations with experienced choral conductors. This generated a large collection of tools and techniques (Cooper, in press). These alone are a valuable resource for novice choral conductors because many of them have not previously been documented in the literature. While the strategies have been used by many choral conductors for a long time, it is useful for others to access this tacit knowledge in written form. The second research question, 'How can a novice choral conductor put these approaches and strategies into practice with community choirs?' was addressed through cycles of design, trial and evaluation, 
which are proposed as a possible format for the informal learning of choral conducting. As is the nature of case studies, my experiences as a single choral conductor undertaking the designbased research process may or may not be applicable to other choral conductors. However, over the three-year period of the research my practice developed significantly as a result.

\section{Notes on the contributor}

Dr Naomi Cooper is a freelance musician, educator and academic based in Sydney, Australia. She has recently completed her $\mathrm{PhD}$, which investigated the process of learning to be a choral conductor. Naomi is in demand as a choral conductor of children's, youth, school, community and university choirs across Sydney. She has presented her research on community choirs both across Australia and internationally (Singapore, Brazil, Japan and Scotland). She has worked as a sessional academic for choir at Western Sydney University and for vocal studies and popular music studies at Macquarie University.

\section{References}

Anderman, E.M. and Anderman L.H. (2009) 'Cognitive apprenticeship'. In Anderman, E.M. and Anderman, L.H. (eds) Psychology of Classroom Learning: An encyclopedia. Detroit: Macmillan Reference, I77-8I.

Backhouse, T. (1995) A Cappella: Rehearsing for heaven: An a cappella choral workbook. Chatswood, NSW: Redback Press.

Backhouse, T. (2010) Freeing the Song: An approach to directing vocal groups. Bondi, NSW: École de Fromage.

Bailey, B.A. and Davidson, J.W. (2005) 'Effects of group singing and performance for marginalized and middle-class singers'. Psychology of Music, 33 (3), 269-303.

Barry, N.H. (1996) 'Promoting reflective practice in an elementary music methods course'. Journal of Music Teacher Education, 5 (2), 6-13.

Bartleet, B.-L. and Hultgren, R. (2008) 'Sharing the podium: Exploring the process of peer learning in professional conducting'. British Journal of Music Education, 25 (2), 193-206.

Beck, R.J., Cesario, T.C., Yousefi, A. and Enamoto, H. (2000) 'Choral singing, performance perception, and immune system changes in salivary immunoglobulin A and cortisol'. Music Perception: An Interdisciplinary Journal, 18 (I), 87-106.

Bolton, G. (200I) Reflective Practice: Writing and professional development. London: Paul Chapman.

Brewer, M. (2004) Fine-Tune Your Choir. London: Faber Music.

Brinson, B.A. (1996) Choral Music Methods and Materials: Developing successful choral programs (grades 5 to 12). New York: Schirmer Books.

Bungay, H., Clift, S. and Skingley, A. (2010) 'The Silver Song Club Project: A sense of well-being through participatory singing'. Journal of Applied Arts and Health, I (2), 165-78.

Busch, B.R. (1984) The Complete Choral Conductor: Gesture and method. New York: Schirmer Books.

Chadwick, S. (20II) 'Lift every voice and sing: Constructing community through culturally relevant pedagogy in the University of Illinois Black Chorus'. International Journal of Community Music, 4 (2), I47-62.

Clift, S. and Hancox, G. (2010) 'The significance of choral singing for sustaining psychological wellbeing: Findings from a survey of choristers in England, Australia and Germany'. Music Performance Research, $3(1), 79-96$.

Collins, D.L. (1993) Teaching Choral Music. Englewood Cliffs, NJ: Prentice Hall.

Cooper, N. (2013a) 'Directing the flow of popular and world musics in community choirs: A learning choral director's perspective'. In Wilson, O. and Attfield, S. (eds) Shifting Sounds: Musical flow: A collection of papers from the 2012 IASPM Australia/New Zealand Conference. Dunedin: International Association for the Study of Popular Music, 34-44.

Cooper, N. (2013b) 'Impacting communities: Tools and techniques for empowering untrained singers to sing in a group'. In Merrick, B. and Forrest, D. (eds) Redefining the Musical Landscape: Inspired 
learning and innovation in music education: Proceedings of the XIX National ASME Conference. Parkville, VIC: Australian Society for Music Education, 60-7.

Cooper, N. (2014) 'Seeking a "true" approach for directing non-notation reading choirs: A literature review'. In Lunn, J. and Bizjak, S. (eds) The Truth is Out There. Perth, WA: Black Swan Press, 78-93.

Cooper, N. (in press) 'Techniques and tools for music learning in Australian community choirs'. In Tolmie, D., Cain, M., Bartleet, B.-L., Power, A. and Shiobara, M. (eds) Community Music in Oceania: Many voices, one horizon. Honolulu: University of Hawaii Press.

Difrances, D. (2006) Zero to Sixty in Record Time: How to build a secondary choral program from scratch. Ashland, $\mathrm{OH}$ : Red Chicken Publishing.

Durrant, C. (1994) 'Towards a model of effective communication: A case for structured teaching of conducting'. British Journal of Music Education, II (I), 57-76.

Durrant, C. (2003) Choral Conducting: Philosophy and practice. New York: Routledge.

Fetterman, D.M. (1989) Ethnography: Step by step. Newbury Park, CA: Sage Publications.

Flick, U. (2002) An Introduction to Qualitative Research. 2nd ed. London: SAGE Publications.

Fredrickson, S. (2004) Popular Choral Handbook: New techniques for pop, jazz, and show choir directors. New Orleans: Scott Music Publications.

Garretson, R.L. (1998) Conducting Choral Music. 8th ed. Upper Saddle River, NJ: Prentice Hall.

Glaser, B.G. (1965) 'The constant comparative method of qualitative analysis'. Social Problems, 12 (4), 436-45.

Gorelick, B. (200I) 'Planning the perfect choral rehearsal'. Music Educators Journal, 88 (3), 28-60.

Gridley, H. (2010) 'In the middle of the sound: Group singing, community mental health and wellbeing'. UNESCO Observatory Journal of Multi-Disciplinary Research in the Arts, 2 (I), I-20.

Gumm, A.J. (2010) 'The speechless rehearsal'. Choral Journal, 50 (7), I6-2I.

Hensley, D.L. (2004) 'Student Times: Choosing the right graduate program for you: Many ideas to consider, many questions to answer - Part II: Which graduate program?'. Choral Journal, 44 (8), 55-8.

Holly, M.L. (1989) 'Reflective writing and the spirit of inquiry'. Cambridge Journal of Education, I9 (I), 7I-80.

Holst, I. (1973) Conducting a Choir: A guide for amateurs. London: Oxford University Press.

Hughes, D., Monro, V., Power, A., Lemon-McMahon, B., Powell, S. and Cooper, N. (2014) 'Approaches to singing: "Snapshots" of Australian contexts'. Australian Voice, 16, I-I I.

Hylton, J.B. (1995) Comprehensive Choral Music Education. Englewood Cliffs, NJ: Prentice Hall.

Johns, C. (2009) Becoming a Reflective Practitioner. 3rd ed. Chichester: Wiley-Blackwell.

Jordan, J. and Mehaffey, M. (200I) Choral Ensemble Intonation: Method, procedures and exercises. Chicago: GIA Publications.

Joseph, D. (2004) 'The practice of design-based research: Uncovering the interplay between design, research, and the real-world context'. Educational Psychologist, 39 (4), 235-42.

Kemp, M. (2009) The Choral Challenge: Practical paths to solving problems. Chicago: GIA Publications.

Kennedy, M.C. (2009) 'The Gettin' Higher Choir: Exploring culture, teaching and learning in a community chorus'. International Journal of Community Music, 2 (2-3), 183-200.

Kreutz, G., Bongard, S., Rohrmann, S., Hodapp, V. and Grebe, D. (2004) 'Effects of choir singing or listening on secretory immunoglobulin A, cortisol, and emotional state'. Journal of Behavioral Medicine, 27 (6), 623-35.

LeCompte, M. and Preissle, J. (1993) Ethnography and Qualitative Design in Educational Research. 2nd ed. San Diego: Academic Press.

Marsick, V.J. and Watkins, K.E. (20I5) Informal and Incidental Learning in the Workplace. New York: Routledge.

Masso, A. (2013) Community Choirs in Australia. Music in Communities Network. Online. http://musicaustralia. org.au/wp-content/uploads/2014/08/Research-Report-Community-Choirs-In-Australia-CommunityPublished-Dec-2013.pdf (accessed 29 July 2017).

McGill, S. and Volk, E. (2007) Beyond Singing: Blueprint for the exceptional choral program. Milwaukee, WI: Hal Leonard.

McIntyre, P. (2006) 'Creative practice as research: "Testing out” the systems model of creativity through practitioner based enquiry'. In Speculation and Innovation: Applying practice led research in the creative industries. Brisbane: Queensland University of Technology. Online. http://arts.brighton.ac.uk/_data/ assets/pdf_file/0019/43093/McintyreP.pdf (accessed 29 July 2017).

McRae, S.W. (1991) Directing the Children's Choir: A comprehensive resource. New York: Schirmer Books. 
Neuen, D. and Bonamico, P. (2002) Choral Concepts. Belmont, CA: Schirmer/Thomson Learning.

Orland-Barak, L. (2006) 'Convergent, divergent and parallel dialogues: Knowledge construction in professional conversations'. Teachers and Teaching: Theory and Practice, 12 (I), |3-31.

Rickwood, J. (2010) 'Singing in between: Re-visioning intercultural community singing'. Paper presented at the New Zealand Musicological Society and the Musicological Society of Australia Joint Conference, University of Otago, Dunedin, New Zealand, 2-4 December 2010.

Roe, P.F. (1994) Choral Music Education. 2nd ed. Prospect Heights, IL: Waveland Press.

Roffey-Barentsen, J. and Malthouse, R. (2013) Reflective Practice in Education and Training. 2nd ed. London: SAGE Publications.

Schön, D.A. (1983) The Reflective Practitioner: How professionals think in action. New York: Basic Books.

Schön, D.A. (1987) Educating the Reflective Practitioner. San Francisco: Jossey-Bass.

Telfer, N. (1995) Successful Warmups (Conductor's Edition). San Diego: N.A. Kjos Music.

Timperley, H. (20I5) Professional Conversations and Improvement-Focused Feedback: A review of the research literature and the impact on practice and student outcomes. Melbourne: Australian Institute for Teaching and School Leadership. Online. www.aitsl.edu.au/docs/default-source/default-document-library/ professional-conversations-literature-review-oct-20I5.pdf?sfvrsn=fc2ec3c_0 (accessed 29 July 2017).

Townsend, R.T. (1996) 'The Music Teaching and Learning Process in an African-American Baptist Church'. PhD thesis, University of Illinois, Urbana-Champaign.

Unwin, M.M., Kenny, D.T. and Davis, P.J. (2002) 'The effects of group singing on mood'. Psychology of Music, $30(2), 175-85$.

Varvarigou, M. and Durrant, C. (20II) 'Theoretical perspectives on the education of choral conductors: A suggested framework'. British Journal of Music Education, 28 (3), 325-38.

Wang, F. and Hannafin, M.J. (2005) 'Design-based research and technology-enhanced learning environments'. Educational Technology Research and Development, 53 (4), 5-23.

White, J.P. (1982) 'Significant developments in choral music education in higher education between 1950-1980'. Journal of Research in Music Education, 30 (2), 121-8.

\section{Related articles published in the London Review of Education}

The paper was published in a special feature of the journal called: 'Music education in context', edited by Hilary McQueen and Maria Varvarigou. The other articles in the feature are:

Black, P. (2017) 'On being and becoming a jazz musician: Perceptions of young Scottish musicians'. London Review of Education, I5 (3), 339-57.

Gande, A. and Kruse-Weber, S. (2017) 'Addressing new challenges for a community music project in the context of higher music education: A conceptual framework'. London Review of Education, I5 (3), $372-87$.

Hallam, S. (2017) 'The impact of making music on aural perception and language skills: A research synthesis'. London Review of Education, 15 (3), 388-406.

Hart, A. (2017) 'Towards an effective freeware resource for music composition in the primary classroom'. London Review of Education, 15 (3), 407-24.

Holmes, S. and Hallam, S. (2017) 'The impact of participation in music on learning mathematics'. London Review of Education, 15 (3), 425-38.

Johnson, C. (2017) 'Teaching music online: Changing pedagogical approach when moving to the online environment'. London Review of Education, 15 (3), 439-56. 
Minors, H.J., Burnard, P., Wiffen, C., Shihabi, Z. and van der Walt, J.S. (2017) 'Mapping trends and framing issues in higher music education: Changing minds/changing practices'. London Review of Education, 15 (3), 457-73.

Rodgers, D. (2017) 'Community music as a vehicle for tackling mental health-related stigma'. London Review of Education, 15 (3), 474-87.

Sarazin, M. (2017) 'Can student interdependence be experienced negatively in collective music education programmes? A contextual approach'. London Review of Education, 15 (3), 488-504. 